\title{
La representación de los trabajadores informales: el Triunvirato de San Cayetano
}

\author{
The Representation of Informal Workers: The Triunvirato de San Cayetano \\ Juan Pablo Hudson
}

Juan Pablo Hudson es investigador del Consejo Nacional de Investigaciones Científicas y Técnicas en el Instituto de Investigaciones Gino Germani, Argentina.

E-mail: juanpablohudson@hotmail.com

\section{resumen}

Este artículo se propone comprender las concepciones, objetivos y modos de organización que sostienen los movimientos sociales integrantes del denominado Triunvirato de San Cayetano: la Confederación de Trabajadores de la Economía popular, Barrios de Pie y la Corriente Clasista y Combativa. Nuestro objetivo es relevar, desde la mirada de sus máximos referentes, perspectivas en torno al empleo informal, los trabajadores populares, la tensión entre innovación y tradición en el tipo de reclamos específicos que impulsan, la relación con el sindicalismo y fundamentalmente con la propia historia de los movimientos de desempleados. Una hipótesis guía este trabajo: las organizaciones mencionadas no se estructuran a partir de la aceptación o el rechazo del trabajo asalariado, como ocurrió en el nacimiento de los movimientos de desempleados, ni tampoco entienden como transitoria la informalidad laboral, puesto que el mercado laboral ya no otorga opciones. La condición de informales o inempleables es comprendida como crónica. Este es el punto de partida de sus luchas. Se trata de una investigación de corte cualitativa. Se realizaron diez entrevistas a referentes principales de los movimientos sociales durante 2018 en el marco de una investigación previa que incluyó entrevistas con funcionarios gubernamentales en 2016 y 2017.

\section{palabras clave}

economía popular / trabajadores informales / autogestión / movimientos sociales / nuevo tipo de sindicato

\section{summary}

This article aims to provide an understanding of the objectives and ways of organization that support the social movements in the Triunvirato de San Cayetano. The aforementioned is integrated by the following groups: Confederación de Trabajadores de la Economía Popular, Barrios de Pie, and Corriente Clasista $y$ Combativa. Our objective is to consider the perspective of these groups' highest referents and disclose the information gathered. The topics which will be analyzed are: informal employment, popular workers, the tension in the claims between innovation and tradition, the relationship with unions and, fundamentally, with the history of the unemployed movement itself. A hypothesis guides this work: the organizations mentioned above are not structured according to the acceptance or the rejection of paid word, which was the case at the onset of the unemployed movements, nor do they understand their situation as transitory informal work, which the labor market does not consider an option. Their informal or unemployable condition is understood as chronic. This is the starting point of their struggles. This research is qualitative. Ten key leaders of social movements were interviewed in 2018 in the framework of a previous investigation that included interviews to government officials in 2016 and 2017.

\section{keywords}

popular economy / informal workers / selfmanagement / social movements / new type of unions 


\section{Introducción}

En el período 2003-2010 se crearon en la Argentina 5 millones de puestos de trabajo, según cifras oficiales (MTEySS, 2010: 36); al tiempo que hubo una significativa reducción de la precariedad laboral (Palomino y Dalle, 2012). A partir de entonces se detuvo la generación de empleo y se consolidó un persistente porcentaje -entre $25 \%$ y $35 \%$, según las fuentes- de informalidad laboral. Durante estos años de importante crecimiento fue, sin embargo, indispensable la puesta en marcha en paralelo de una creciente estructura de subsidios para generar ingresos entre los sectores informales y los desocupados crónicos. Para esta población excluida, los llamados gobiernos progresistas (Néstor Kirchner 2003-2007; Cristina Fernández 2007-2011 y 2011-2013) promovieron este tipo de estrategias que llamaremos post-salariales. El método elegido fue el impulso de cooperativas de trabajo, una iniciativa que ya habían puesto en marcha masivamente los movimientos de desempleados y las empresas recuperadas por trabajadores en la década de 1990 y a inicios de este siglo, con el objetivo de atravesar el desastre económico provocado por las políticas neoliberales.

Dos áreas gubernamentales protagonizaron las políticas de subsidios entre 2003 y 2015: el Programa de Trabajo Autogestionado (desde ahora PTA), creado en 2004 por el Ministerio de Trabajo, Empleo y Seguridad Social ${ }^{1}$ (MTEySS), cuyo objetivo primordial fue la gestación de un tercer sector productivo en base a empresas recuperadas por trabajadores (ERT), la formalización de proyectos cooperativos preexistentes entre desocupados, y la incubación de emprendimientos asociativos directamente desde el propio Estado. A través de la inyección de fondos y la creación de redes sectoriales, se intentó tornar sustentables estos tres tipos de cooperativas para que pudieran subsistir en sus respectivos mercados.

Los otros subsidios fueron promovidos por el Ministerio de Desarrollo Social de la Nación (MDSN) bajo otra impronta. En 2003, se creó el Plan Manos a la Obra, que funcionaba a partir del financiamiento de pequeños emprendimientos productivos a través de la compra de maquinarias. Pero el proyecto más ambicioso fue el Programa de Inclusión Social con Trabajo (PRIST), iniciado en 2009 como una estrategia para paliar los efectos de la crisis financiera internacional y el incipiente estancamiento de la creación de empleo en blanco que antes mencionábamos. Su misión fue forzar (Lo Vuolo, 2010; Vuotto, 2011; Hopp, 2015) asociaciones cooperativas entre los calificados como inempleables (Scarfó, Highton y Hopp, 2009; Natalucci, 2012) por el mercado laboral. Para este tipo de emprendimientos colectivos no hubo mayores expectativas sobre su capacidad de producción y comercialización en el mercado, por lo que se los redujo a prestatarios de servicios elementales (arreglo de calles, zanjas, forestación, etcétera) en los municipios. La intención principal fue que las cooperativas funcionaran como eficaces canales de transferencia de subsidios que evitaran la caída en la pobreza de esa población excluida de manera estructural.

Una característica central de las políticas públicas basadas en subsidios al cooperativismo es que surgieron como efecto de investigaciones sistemáticas llevadas adelante por el MTEySS y el MDSN sobre los modos específicos de autogestión 
sostenidos por los movimientos sociales. El resultado fue una traducción estatal de esas cooperativas de subsistencia creadas para asegurar la manutención básica para los sectores más empobrecidos por la economía de mercado.

Otra razón principal por la que se forzó a los sectores informales y desocupados crónicos a que formaran cooperativas fue la necesidad política de organizar y tornar aprehensibles poblaciones y territorios denominados calientes como, por ejemplo, las localidades más populosas del conurbano bonaerense. De hecho, después del cambio de gobierno nacional acontecido en diciembre de 2015, la alianza Cambiemos encabezada por el presidente Mauricio Macri (2015-2019) encontró justamente en el MTEySS y en el MDSN estructuras de subsidios que le permitieron el acceso a periferias urbanas en donde el empleo en blanco es un privilegio de minorías obreras y/o el recuerdo de otras generaciones laborales. Para desconcierto de los análisis más maniqueos sobre el nuevo gobierno, a partir de la asunción de Mauricio Macri no solo no hubo recortes, sino que se incrementaron súbitamente los presupuestos del PTA y el PRIST. Los aumentos, vale aclararlo, coincidieron con una masiva demanda de ayuda financiera de las cooperativas en un contexto social, laboral, económico y financiero realmente crítico provocado por las políticas de ajuste permanente implementadas por el gobierno de la alianza Cambiemos. Lo mismo ocurrió en el caso de aquellas poblaciones que, mediante las organizaciones sociales, reclamaron subsidios como un paliativo a la vertical caída de los ingresos o, directamente, por la caída en la pobreza e incluso en la indigencia.

Con respecto a los cambios implementados a partir del fin de los gobiernos progresistas, el gobierno de Mauricio Macri inició una investigación sobre la sustentabilidad de las múltiples cooperativas financiadas por el Estado nacional. Los criterios aplicados fueron únicamente empresariales: evaluaron si las cooperativas eran sustentables en el mercado y si tenían capacidad de generar empleo. En los gobiernos de Néstor Kirchner y Cristina Fernández también se separaba entre emprendimientos competitivos (los financiados por el PTA en el MTEySS) y de subsistencia (los pertenecientes al PRIST en el MDSN), pero no se decidió -tal como sí lo hizo Cambiemos- eliminar el requisito de organizarse de manera cooperativa para obtener los subsidios. El kirchnerismo forzó un sujeto colectivo (los inempleables, es decir, los desempleados crónicos) como destinatario de los subsidios; el macrismo, por el contario, fijó como beneficiarios a los individuos. El argumento esgrimido por Cambiemos fue que las cooperativas conformadas nunca funcionaron como tales, dado su carácter forzoso y tampoco, salvo excepciones (Hudson, 2018), lograron dar un salto mínimo de productividad y competitividad. Para los reducidos casos en que se comprobaron capacidades reales de producción, comercialización y empleabilidad, se crearon áreas como la Subsecretaría de Economía Popular en el MDSN y se fortaleció, durante 2016 y 2017, la capacidad de financiamiento del PTA en el MTEySS.

La otra ruptura decisiva fueron los cambios en los Entes Ejecutores de los subsidios. Durante los gobiernos progresistas, fueron los municipios. A partir de 2016, en cambio, quienes ejecutaron los planes fueron las organizaciones sociales que 
analizaremos en los próximos apartados. Esto significó una importante transferencia de fondos hacia tres organizaciones principales reunidas en el denominado Triunvirato de San Cayetano: la Confederación de Trabajadores de la Economía Popular (CTEP), Barrios de Pie, y la Corriente Clasista y Combativa (CCC). Esos importantes volúmenes de dinero transferidos desde el Estado fueron destinados a la compra de materias primas, de ropa de trabajo, o al pago de impuestos. Sin embargo, esos fondos no se utilizaron para los ingresos económicos individuales de los trabajadores, quienes siguieron recibiendo el pago directamente a través de depósitos bancarios. La postergación de los municipios seguramente respondió a una lectura gubernamental de las relaciones de fuerza políticas en el decisivo conurbano bonaerense.

El cambio de los entes ejecutores fue el antecedente inmediato a la aprobación parlamentaria, en diciembre de 2016, de la Ley de Emergencia Social. Esta ley $\left(\mathrm{N}^{\circ} 27.345\right)$ creó un Consejo de la Economía Popular, cuya principal tarea fue la generación de un registro nacional de trabajadores de la economía popular. También dispuso el Salario Social Complementario (SSC), bajo la órbita del MDSN, con un presupuesto de treinta mil millones de pesos hasta 2019. La aprobación institucionalizó la oscilación permanente entre el conflicto y los pactos preexistentes entre el Triunvirato de San Cayetano y la flamante alianza Cambiemos. El gobierno se propuso formalizar por escrito acuerdos, en la medida en que se los consideraba indispensables para contener la protesta social en el marco de su severo programa de ajuste. Para las organizaciones, entretanto, fue la oportunidad de robustecer sus estructuras organizativas en base a la obtención de recursos y, en casos como la CTEP, a partir de la absorción de organizaciones de menor tamaño que requirieron de su amparo para garantizar la obtención de planes. Otro objetivo del gobierno nacional fue la progresiva incorporación de los beneficiarios de los distintos subsidios implementados por el MTEySS y el MDSN en una figura única: el Salario Social Complementario. Es decir, un subsidio económico que se considera complementario de los ingresos obtenidos a través de empleos informales. La ley dispuso que dicho salario tenga el valor de la mitad de un salario mínimo, vital y móvil.

El inicio de 2018 marcó otra nueva ruptura relevante. Se trató del nacimiento del programa Hacemos Futuro, bajo la órbita del MDSN, que absorbió los programas integrantes del PRIST (Argentina Trabaja, Ellas Hacen y Barrios Bonaerenses). La principal novedad fue que ya no se subsidió el trabajo sino la finalización de los estudios y la capacitación técnica. En otras palabras, a diferencia del Salario Social Complementario, se consideró que la informalidad era un período pasajero que, con mayor formación y voluntad de emprendimiento, finalizaría luego de la inclusión en un empleo en blanco. También se eliminaron, al menos de manera formal, las cooperativas preexistentes y solo se mantuvieron los pagos individuales.

Tras esta introducción, aclaramos que este artículo se propone comprender, por un lado, las concepciones que tienen referentes de las organizaciones integrantes del Triunvirato de San Cayetano en torno al empleo informal, los trabajadores de la economía popular y la tensión entre innovación y tradición en el tipo de recla- 
mos específicos que impulsan. Por otro lado, de manera complementaria, el tipo de (auto)organización que se proponen y la relación específica con el sindicalismo ortodoxo.

Para tal fin, hemos realizado diez entrevistas a ciertos referentes principales de estas organizaciones durante 2018 y 2019 . Se trata de un trabajo de campo complementario al realizado en 2016 y 2017, en el cual se habían realizado quince entrevistas a funcionarios del MTEySS y del MDSN encargados de las políticas de subsidios y de la relación con las organizaciones sociales.

En el primero de los apartados, llevaremos a cabo una cartografía de una serie de investigaciones en torno a la relación entre el Estado y las organizaciones sociales desde 2003 hasta la fecha, algunas de ellas específicamente sobre la CTEP. En el segundo apartado, analizaremos las concepciones que tienen referentes de la CTEP, Barrios de Pie y la CCC en torno al mercado de trabajo y los objetivos primordiales de sus luchas. Finalmente, en el último, analizaremos el surgimiento de una estructura política -el Triunvirato de San Cayetano- capaz de centralizar la representación de los sectores informales, con principal énfasis en el surgimiento y expansión de la CTEP; así como las continuidades y rupturas con los períodos previos de lucha de los movimientos de desempleados, o también denominados piqueteros.

\section{Investigaciones sobre la economía popular}

Las investigaciones sobre la economía popular y sus organizaciones presentan al menos cuatro etapas, de las cuales repararemos en la más actual, puesto que guarda relación con los objetivos de este artículo. Mencionamos, no obstante, las tres primeras con el fin de establecer una cronología.

Una primera etapa se inaugura a partir del estudio del nacimiento de movimientos sociales como las organizaciones de desempleados (también denominadas piqueteras) y, más adelante, el surgimiento de otros movimientos como las empresas recuperadas por sus trabajadores, los clubes del trueque, las asambleas barriales, entre otros.

Una segunda etapa incluye el estudio de la relación entre estas organizaciones sociales, principalmente de los movimientos piqueteros, y los gobiernos denominados progresistas surgidos entre 2003 y 2015 . Aquellos investigadores que habían abordado los movimientos sociales desde finales de la década del noventa y a partir de las revueltas populares de diciembre de 2001 indagaron la relación entre las organizaciones piqueteras y el kirchnerismo. Es posible observar algunas líneas principales de análisis: la más extendida afirma que los gobiernos a partir de 2003 cooptaron, institucionalizaron y, en definitiva, subordinaron a las organizaciones que habían resistido los embates del neoliberalismo a partir de los cortes de ruta y proyectos productivos autogestionarios (Svampa, 2005; Svampa y Pereyra, 2004; Zibechi, 2008; Fornillo, 2008; Massetti, 2009). La segunda línea da cuenta de un reflujo y una desmovilización con recorte de la autonomía, menos como consecuencia de un activo proceso de cooptación que como evidencia de una nueva legitimación del Estado como regulador de lo social (Rajland y Campione, 2006), 
luego de la crisis de representación de principios del siglo. Una tercera corriente, por su parte, propuso salir del recurrente análisis suscitado a partir del binomio autonomía-cooptación para pasar a pensar en términos de ambivalencias y tensiones permanentes (Schuttenberg, 2014; Natalucci, 2014; Perelmiter, 2010).

En los últimos años, han surgido trabajos que analizan las transformaciones experimentadas por las organizaciones sociales, fundamentalmente a partir del nacimiento y consolidación de la CTEP. El relevamiento de textos (sin pretensión de incluirlos a todos) indica varias aristas importantes para nuestro enfoque. Por un lado, existen trabajos que analizan un aspecto innovador que propone la CTEP respecto de la trayectoria de los movimientos sociales de los noventa: su conformación como un sindicato de nuevo tipo y la demanda de inclusión dentro de la Confederación General del Trabajo (CGT) (Muñoz y Villar, 2017). Estos trabajos ponen el foco menos en su relación histórica con los movimientos piqueteros que en las diferencias y similitudes con la tradición sindical argentina. Allí introduciremos una mirada contrapuesta: para nuestras investigaciones, lo primero es inscribir a la CTEP como una tercera etapa, con sus rupturas y continuidades, del ciclo de luchas abierto a partir del nacimiento del movimiento piquetero en 1996. Una segunda línea de estudios (Gago, 2015, 2016; Lijterman, 2018; Fernández Álvarez, 2018; Fernández Moujan, 2018), cercana a la que propondremos en este trabajo, traza una genealogía política entre los movimientos sociales que supieron cuestionar e incluso poner en crisis la legitimidad política del neoliberalismo y la CTEP.

Otros trabajos con los que coincidimos ponen el énfasis en que la CTEP logra fusionar dos tradiciones: la del movimiento sindical y la tradición de los movimientos y organizaciones sociales/populares (Bruno, Coelho y Palumbo, 2017; Fernández Moujan, 2018). En esta línea también aparecen los aportes de María Inés Fernández Álvarez (2018) y Hugo Serra (2017), quienes comprenden a la CTEP como una construcción colectiva que tensiona las fronteras clásicas entre trabajo formal/informal, asalariado/no asalariado, movimiento obrero/movimientos sociales.

Para finalizar, es indispensable destacar uno de los aspectos más disruptivos de experiencias como la de la CTEP: cuenta con una capacidad de elaboración teórica propia (Grabois y Pérsico, 2014a, 2014b, 2014c, 2014 d; Pérsico y Navarro, 2017; Grabois, 2018). Esto prácticamente no ocurrió en el movimiento piquetero en la década de 1990. Referentes de la CTEP publican libros con definiciones sobre lo que conciben como economía popular, sus alcances, sus protagonistas, su inscripción en la historia reciente de las luchas sociales en la Argentina, análisis minuciosos del sistema capitalista en su etapa actual y la evolución del mercado laboral.

De cualquier modo, los objetivos de este artículo no se limitan al análisis de la CTEP. Nos proponemos analizar las concepciones del Triunvirato de San Cayetano, que incluye a este nuevo sindicato pero también a Barrios de Pie y la CCC.

\section{Organizaciones post-salariales}

El Triunvirato de San Cayetano ${ }^{2}$ (desde ahora el Triunvirato) representa a aquellos sectores que construyen sus propias formas de generar ingresos, es decir, por 
fuera de una relación salarial. Esta autogestión laboral puede ocurrir a cielo abierto, tal como sucede en el caso de cartoneros, vendedores ambulantes, agricultores familiares, entre otros; o al interior de las fábricas como los trabajadores de las empresas recuperadas o de los talleres textiles, por solo nombrar algunos casos. La dimensión clave no es la locación sino el carácter post-salarial de los ingresos obtenidos.

Emilio Pérsico, referente del Movimiento Evita, organización integrante de la CTEP, utiliza una metáfora precisa para analizar la fragmentación del mercado laboral en Argentina como saldo de las políticas neoliberales:

(...) la clase trabajadora está dividida en tres pedazos: la crema, la leche y el agua. La crema en una sociedad como la nuestra es hasta el $20 \%$ de los trabajadores, trabajadores integrados, los trabajadores reconvertidos, dicen ellos, ¿no? Son estos trabajadores que consumen, que compran dólares. Después está otro sector que sí es bastante más grande, que es la leche, que sí es el sector de trabajadores no reconvertidos. Muchos de la UOM, de textiles, no reconvertidos. Finalmente están los trabajadores de la economía popular. Ejemplos: fábricas recuperadas, cooperativas, los cartoneros... Un trabajador de los primeros cobra por encima de las veinte lucas [veinte mil pesos], los otros estarán de veinte a ocho [mil pesos], a siete, o a cinco, y después una gran masa de la economía popular, de trabajadores que se auto-inventaron el trabajo. Que son improductivos en términos capitalistas, que tienen otro tipo de producción que es difícil de comprender para el capitalismo (citado en Abal Medina, 2017).

Del testimonio surgen dos preguntas. ¿Efectivamente la economía popular es un tipo de producción "difícil de comprender para el capitalismo" en su fase financiera? ¿O es un modo de tercerizar determinadas labores productivas y comerciales no rentables pero indispensables para el funcionamiento de la economía de mercado? El propio Pérsico y Juan Grabois, referente del Movimiento de Trabajadores Excluidos, integrante también de la CTEP, lo confirman cuando escriben que la economía popular no es ajena ni está separada del mercado y las empresas (Grabois y Pérsico, 2014a). Existen múltiples conexiones en el plano de la producción y el consumo. De hecho, actividades autogestionadas a baja escala de la economía popular participan de manera indirecta en cadenas de valor de las grandes corporaciones. El propio sector financiero, por ejemplo, a través de préstamos usurarios explota la imperiosa necesidad de contar con un mínimo de capital para poner en marcha pequeños emprendimientos productivos informales.

Veamos el siguiente análisis de Emilio Pérsico sobre el sector que representa CTEP:

Los compañeros estaban haciendo cosas, estaban yendo a vender chipá, salían a vender pan, no se quedaban en la casa, resistían la falta de empleo y hacían cosas. (...) Se resistían a vivir en la marginalidad. Y empezamos a construir una nueva economía. Y a partir de ahí empeza- 
mos a construir una teoría, que fue una idea de la economía popular. Primero fuimos piqueteros que salíamos a cortar ruta, después fuimos organizaciones sociales, (...) y después nos enorgullece constituirnos como un sindicato (Capital Federal, 2018).

En el testimonio claramente inscribe a las organizaciones actuales de la economía popular como una tercera fase del movimiento de desempleados nacido a mediados de la década de 1990. Sinteticemos esas fases, según lo expresado por Pérsico: primer período (1996-2003), desde el nacimiento de los movimientos piqueteros, la rebelión popular del 19 y 20 de diciembre de 2001, hasta el inicio del gobierno de Néstor Kirchner; segundo período (2003-2015), determinado por el reconocimiento estatal de ciertas organizaciones piqueteras, con la transferencia de subsidios a través de los planes sociales y la incorporación de militantes territoriales en la propia gestión gubernamental; determinado también por los conflictos con las organizaciones que se mantuvieron a distancia del Estado y en franco conflicto como fue el caso de la CCC; y el tercer período (2015-2019), abierto a partir del cambio de gobierno nacional en diciembre de 2015, con el final de los llamados gobiernos progresistas y el inicio de un gobierno de derecha que paradójicamente permitió un voluminoso crecimiento de las estructuras organizativas del Triunvirato de San Cayetano.

En la primera fase (1996-2003), encontramos una discusión en el interior de las organizaciones piqueteras: si los cortes de ruta y la (auto)organización en cooperativas debían desarrollarse hasta tanto cesara la crisis industrial y los desocupados lograran ser paulatinamente incluidos en las empresas, o bien si los crecientes niveles de autogestión (micro)productiva eran una perspectiva política definitiva para no volver a someterse a la explotación bajo patrón. "Nosotros no queremos inclusión. Por lo menos yo no quiero volver a ser explotado, no quiero volver a tener a la Fortabat ${ }^{3}$ o a Macri ${ }^{4}$ de patrón, eso seguro. Yo no peleo para que me vuelvan a explotar", declaraba en 2002 un referente del Movimiento de Trabajo Desocupados de San Francisco Solano, Florencio Varela, provincia de Buenos Aires (Colectivo Situaciones, 2003: 59). Este enfoque, que llamaremos "autonomista", rechazaba "solicitar el reingreso a un segmento de la deshecha estructura social, que solo podría - eventualmente- aceptarlos en condiciones que ellos [los trabajadores desocupados] han aprendido a despreciar" (Colectivo Situaciones, 2003: 31).

Por el contrario, había otras organizaciones piqueteras, que llamaremos "institucionalistas", para las que "la fuerte herencia de la sociedad salarial -en su impronta fabril-marca todavía la concepción de lo que se entiende por "trabajo genuino" y el "horizonte de su reconstrucción" (Svampa, 2005: 253). Desde esta segunda posición nunca cesó el deseo de retornar a una relación salarial. Allí encontramos a la CCC, que forma parte, actualmente, del Triunvirato.

Sin embargo, reparemos en un aspecto clave de aquella discusión. A pesar de las diferencias políticas, ambas posturas coincidían en un punto: todavía existían expectativas de un crecimiento económico que permitiera (re)incluirlos. Las organizaciones "autonomistas" rechazaban esta opción porque querían mantenerse 
a distancia de los patrones; y las "institucionalistas", por su parte, añoraban recuperar un estatus laboral, económico y social, lo mismo que una identidad obrera en crisis.

Esta última expectativa se cumplió en parte entre 2003 y 2011, cuando el crecimiento del empleo en blanco permitió la inclusión de trabajadores que habían padecido el desempleo en los noventa y durante la crisis que inauguró el siglo XXI. Durante esos años, se incorporaron un millón de "obreros calificados de la industria y de servicios básicos asociados, que incluyen las actividades vinculadas con la industria manufacturera, la construcción, transporte, almacenamiento, comunicaciones, electricidad, gas y agua" (Palomino y Dalle, 2012: 209). En el tercer trimestre de 2003, según datos del Instituto Nacional de Estadística y Censos (INDEC), la tasa de asalariados en la Argentina era del 66,4\%, de los cuales el 37,4\% estaban registrados y el $29 \%$ no. Ocho años más tarde, en 2011, la tasa de asalariados había ascendido al 75,5\% (+9\%), los registrados pasaron a representar el 49,88 (+12,4\%) y los no-registrados disminuyeron a un $25,7 \%(-3,3)$ (Palomino y Dalle, 2012).

Sin embargo, esa creación de empleo en blanco al compás de la recuperación industrial se detuvo en 2011. Según datos de la OIT en base a informes del MTEySS, en 2011, la informalidad laboral (medida como el porcentaje de trabajadores no registrados en la seguridad social) para el total de los ocupados se ubicó en un 42,7\%. Esta tasa de incidencia alcanza el $37 \%$, para los trabajadores asalariados, y el 59\%, entre los independientes (descomponiéndose luego en 64\%, entre los cuentapropias, y 20\%, entre los patrones). Asimismo, se observa que del total de los trabajadores informales, el $65 \%$ son ocupados en relación de dependencia; el 31\%, trabajadores por cuenta propia; y el $4 \%$ restante se distribuye entre patrones y trabajadores familiares sin salario (2013: 31).

Este dato objetivo marca un quiebre en las expectativas de las organizaciones sociales que provenían de los movimientos piqueteros. Desde entonces, el horizonte ya no fue recuperar un trabajo formal, aun cuando públicamente no renunciaran a ese reclamo, como ha sido el caso de la CCC. Bajo esta premisa nace la CTEP en 2011 y se reestructuran Barrios de Pie y, sobre todo, la CCC. Lo decimos a modo de primera hipótesis: estas organizaciones no se estructuran ya a partir de la aceptación o el rechazo del trabajo asalariado como en la primera fase, ni tampoco entienden como transitoria esa situación laboral como pregonaban los gobiernos progresistas en la segunda fase. Su especificidad, más allá de los discursos públicos, es que el mercado laboral zanjó esa discusión y ya no otorga opciones. De allí que acepten que la informalidad y la desocupación son una condición estructural, permanente. Después -insistimos-, públicamente, organizaciones como la CCC, pero también las otras, siguen demandando empleo en blanco.

Veamos las perspectivas de distintos referentes del Triunvirato:

(...) empezamos a discutir otras cosas, empieza a salir la idea de la economía popular; empezamos a sentirnos como trabajadores y empe- 
zaron los compañeros -ya más allá de las organizaciones-a levantarse y a decir "esto va para largo, va para siempre"; y empezaron a buscar, ya no esperar que los reincorpore la fábrica porque la fábrica estaba medio abandonada y los chicos iban a jugar adentro. (...) Aparece que ya era un problema más profundo, es el modelo (...) (Referente CTEP, 2018).

Hay una concepción que prima en la sociedad. Esta idea de que de alguna manera estamos en una crisis pero el desarrollo del capitalismo va a resolver esa crisis y va a incluir a todos. Era una charla que teníamos con Carlos Tomada [exministro de Trabajo entre 2003 y 2015], por ejemplo. Todos aquellos trabajadores que no estaban incluidos con todos sus derechos, a partir del desarrollo del modelo iban a entrar. Y nosotros por las cuentas que sacábamos no nos daba que iban a entrar, no iba a entrar nadie. Que el 35\% del trabajo no registrado quedaba ahí y que gran parte de ese trabajo era parte de la economía popular. Lamentablemente tuvimos razón (Referente CTEP, Capital Federal, 2018).

La economía popular es el conjunto de actividades laborales que el pueblo se inventó para sobrevivir afuera del mercado formal. Es cierto que siempre hubo compañeros que, en vez de laburar en una fábrica, se ponían un kiosco o un tallercito para venderles a los obreros, pero esas eran opciones individuales antes, ahora no queda otra que inventarse el trabajo (Pérsico, Grabois, 2014a: 31).

Hay gente que no va a entrar nunca más. Yo soy consciente que en una fábrica no te van a tomar a un trabajador de cincuenta años o una madre con cinco hijos, o una persona mayor (Referente CCC, La Matanza, 2018).

Nosotros creemos que no hay lugar para todos. Eso es un dato concreto. En Europa se resuelve repartiendo las horas de trabajo o se resuelve con un ingreso universal. Nosotros creemos que acá ese debate está lejos, que el que introduce este debate es el espacio que genera la CTEP, Barrios de Pie y la CCC (Referente Barrios de Pie, Capital Federal, 2018).

Como afirmábamos, la CCC manifiesta mayores resistencias a aceptar esa condición estructural que, desde la perspectiva de la CTEP y Barrios de Pie, impone el capitalismo en su fase financiera. Así lo manifiesta una de sus referentes en Capital Federal:

(...) aspiramos a volver al mercado de trabajo. Por eso celebramos si hay desarrollo de la pequeña y mediana industria. Porque hay distintas corrientes dentro de la economía popular [hacia el interior del Triunvirato]: hay quien dice que ya no se va a poder volver más al trabajo 
formal y cada uno es el dueño de su propio trabajo y hay que desarrollar el auto empleo o lo que se llama la economía popular, la economía social, o sea, el cuentapropismo. Nosotros, en principio, no estamos de acuerdo, creemos que sí se puede volver al mercado de trabajo con una política que beneficie a esa misión. Teniendo en cuenta que las grandes potencias, las grandes empresas, pretenden un mercado laboral reducido, para obtener más ganancias y dedicarse a la especulación financiera o a otras cosas. (...) Nosotros decimos es posible si hubiera un gobierno que quiera desarrollar la industria nacional, que quiera desarrollar la pequeña y mediana empresa que es la que da trabajo (Referente CCC, Capital Federal, 2018).

De todos modos, más allá de esa aspiración política, acto seguido esta misma referente afirma lo siguiente: "Muchos quedaron afuera del mercado de trabajo por completo porque tienen más de cincuenta años o más de cuarenta y pico y ya no puede pertenecer más al mercado de trabajo" (Referente CCC, Capital Federal, 2018).

Se suma el análisis del máximo referente de la $\mathrm{CCC}$, en el que sobresalen tensiones y ambivalencias en torno a los modos de concebir el mercado de trabajo actual:

Hay un sector que no va a entrar nunca a la producción, al trabajo formal. Muchos de ellos por la edad, son jóvenes para jubilarse y viejos para la producción, de cuarenta y cinco años para arriba. Yo mismo el oficio que tenía en la industria era de obrero trasfilador. Antes el trasfilador era un año para aprender, pero era medio artesano. Hoy es todo computarizado. (...) Por eso nosotros apuntábamos en estos planes sociales, no como pasa hoy con las capacitaciones que no es serio, sino otras para ver cómo preparo si el país mejora y empieza a haber trabajo. Ningún gremio tiene, por ejemplo, capacitación tecnológica para prepararte para el futuro. Otros compañeros por razones de salud tampoco van a entrar nunca el mercado formal. Creo que va a haber una parte inmensa que va a quedar afuera (Referente CCC, La Matanza, 2018).

En definitiva, en la práctica concreta, el Triunvirato elabora un programa reivindicativo basado en una situación estructural del mercado de trabajo contemporáneo: "no hay lugar para todos". Es un tipo de programa diferente al desplegado por los movimientos sociales que lo anteceden, incluso respecto de lo que estas mismas organizaciones impulsaban, como es el caso del Movimiento Evita y la mencionada CCC. Si ya no es posible volver a ser asalariados, el objetivo ahora es otro: los trabajadores informales deben ser reconocidos por el Estado y obtener derechos similares a los que gozan los trabajadores formales (salario, obra social, aguinaldo, paritarias). De allí las incipientes alianzas con la Confederación General del Trabajo (CGT). Nuevamente incorporamos el análisis de dos referentes del Triunvirato: 
El planteo nuestro es que el trabajador que queda afuera de la formalidad del trabajo y es capaz de crear alguna suerte de trabajo que le permita subsistir en principio, (...) tenga los mismos derechos o parecidos a los de un trabajador formal. (...) Nosotros decimos que un compañero o una compañera que subsiste vendiendo chipá, que lo hace, lo produce o arma una cooperativa y sale a vender y gana 15 mil pesos por mes, tiene que tener un salario social complementario que le garantice la canasta básica. Para no caer en la indigencia. ¿Eso qué lógica tiene? Que tiene que tener el salario social [complementario], que tiene que tener el apoyo del Estado para insumos, subsidios para que la harina no le salga tan cara, y una parte de la producción, sobre todo de bienes más durables, no solo de alimentos, tiene que ser comprado por el Estado (Referente CTEP, Capital Federal, 2018).

Nosotros realmente creemos que, por supuesto, una cosa es un modelo asentado en la valorización financiera y en la bicicleta financiera como este [gobierno de la alianza Cambiemos 2015-2019] y otra cosa es un gobierno productivo que seguramente incorpora más. Ahora, aun en la experiencia del kirchnerismo [2003-2015], te queda afuera una parte. (...) La gente creó un espacio de economía informal, ya sea con sus actividades de subsistencia, con sus esquemas de comercialización que son todas las ferias y todos los espacios de circulación de plata y de producción de riqueza. (...) Entonces la pregunta es qué hacés vos con eso: discutir nuevos derechos acompañando la misma experiencia que hace la gente (Referente Barrios de Pie, Capital Federal, 2018).

En resumen, la lucha real ya no pasa por el pasaje de la informalidad a la condición asalariada sino por mejorar las condiciones de los informales que se inventaron sus propias formas de generar ingresos. Segunda hipótesis: por un lado, esta estrategia se muestra audaz e innovadora en la medida en que pone en diálogo figuras y narrativas que vertebraron el mundo asalariado con trabajadores que justamente quedaron expulsados de manera crónica de una relación salarial. Al mismo tiempo, se evidencian rasgos tradicionales, puesto que las organizaciones sociales basan sus reivindicaciones en un mundo laboral asalariado en crisis e, incluso, desde ciertas perspectivas, en vías de extinción. En otras palabras, para dar institucionalidad y mayor volumen a un actor novedoso (los inempleables/trabajadores populares), las organizaciones se refugian en un repertorio de reivindicaciones propias de la vieja tradición sindical.

El proceso que mejor evidenció esta ambigüedad fue la aprobación legislativa de la Ley de Emergencia Social en diciembre de 2016. Esta Ley ( $\left.N^{\circ} 27.375\right)$, impulsada por el Triunvirato de San Cayetano con apoyo de la CGT, significó el nacimiento del Salario Social Complementario, entendido como una suma de dinero mensual transferida por el Estado a cada trabajador informal a fin de que complemente los ingresos obtenidos a través de actividades productivas. Este rele- 
vante logro posibilita el reconocimiento estatal de las actividades productivas de la economía popular y también reconoce a sus protagonistas como trabajadores. Lo que antes era un oxímoron (salario e informalidad laboral), ahora es una relación complementaria. Así lo analizan referentes:

Después de la dictadura [1976-1983] empieza un proceso paulatino de concentración económica que te expulsa del trabajo pero además te deja sin salario. Acá les estamos pidiendo que den un pedacito de lo que nos sacaron. Yo estaba empecinado que había que imponer en la sociedad la idea del salario y que nosotros no queremos hablar más de planes, porque es lo que te corresponde por derecho. Por eso es social, porque lo paga toda la sociedad, y complementario porque complementa el ingreso que vos te generaste con tu forma de trabajar (Referente CTEP, Capital Federal, 2018).

Nosotros peleamos por la dignidad de esa economía popular. Para que en los sectores de la economía popular se cumpla la constitución, se cumplan las leyes sociales, es por eso que queremos parecernos a la historia de nuestro movimiento obrero. Por eso es que hablamos de paritarias sociales cuando nos ponemos a discutir las condiciones del sector con el Estado; por eso no hablamos más de planes sociales, queremos salario social complementario (Referente CTEP, Capital Federal, 7 de agosto de 2018).

Nosotros venimos de la Ley de Emergencia Social, que implica una caracterización de la economía popular; eso significa eliminar todos los planes sociales y reemplazarlos por Salarios Sociales Complementarios, que es un derecho más que un plan social. Así como hay un ingreso universal para los $\operatorname{chicos}^{5}$, tiene que haber desde el punto de vista del mercado laboral un ingreso para todo el trabajador que realiza una actividad en el marco de la economía popular y que eso le dé un piso de ingresos desde una mirada productiva (Referente Barrios de Pie, Capital Federal, 14 de septiembre de 2018).

(...) Creo también que esa mirada acepta que lo que hace la gente es una inclusión desde una identidad, que desde lo simbólico rejerarquiza una situación de pobreza. O sea, (...) una cosa es percibir un plan social y otra cosa es percibir un programa de empleo e ir a un lugar que hace las veces de fábrica; y que vos te sentís que sos parte y tenés un horario, sos parte de un universo que hace que tu subjetividad esté mucho más valorizada (Referente Barrios de Pie, Capital Federal, 2018).

[Ya durante el inicio del kirchnerismo] nosotros queríamos que las cooperativas sociales se transformaran en unas cooperativas que trabajaran para el Estado. Pero el Estado se tenía que hacer cargo de 
las cargas sociales de cada uno. (...) Le presentábamos de qué manera entendíamos nosotros que cada compañero tenía que recibir el sueldo del Estado para trabajarle al Estado a través de cooperativas. (...) En este caso queríamos obra social también, como cualquier trabajador, cosa que no logramos avanzar en ese sentido (Referente CCC, La Matanza, 2018).

De los testimonios se desprende una dimensión antes nombrada: la importancia para los trabajadores de la economía popular de poder obtener derechos laborales pero también de incluirse en una trama simbólica propia del mundo asalariado. Los términos utilizados - rejerarquiza, valorizada, hace las veces de fábrica- dejan en claro el valor identitario que todavía cumple esta trama discursiva, a pesar de la permanente descomposición de ese régimen laboral en las últimas cuatro décadas. Retomemos el análisis de la figura del Salario Social Complementario:

El compañero está trabajando y es un trabajador, pero no le alcanza para vivir, entonces acepto sí la limosna del Estado y el plan social, pero no la quiero como plan, la quiero como salario, porque es la dignidad del salario la que te recupera a vos con la dignidad ante tu familia, ante la sociedad, ante los otros (Referente CTEP, Capital Federal, 13 de agosto de 2018).

En el fondo tiene que ver con una mirada más sindical, obrerista. Sin dudas. Pero que no deja de ser una invención en relación con el mundo de los movimientos sociales. Es una vuelta de tuerca interesante. (...) La búsqueda de articulación, más allá de las tradiciones y las características del movimiento obrero, adquirió mucha relevancia. Y me parece que no deja de ser una mirada original vista desde el proceso de los movimientos sociales (Referente Barrios de Pie, Capital Federal, 2018).

Nuevamente surge la distinción entre los diferentes ciclos de luchas sociales en las últimas dos décadas. La ruptura se da con relación al repertorio de reivindicaciones propio de las primeras dos fases de los movimientos sociales precedentes. Tercera hipótesis: no hay invención de nuevas narrativas por parte del Triunvirato sino una innovadora recombinación de figuras propias de la tradición asalariada con trabajadores y escenarios (calles, cooperativas, pequeños campos, etcétera) anómalos para ese régimen laboral.

Para finalizar este apartado, remarcamos un punto de confluencia poco explorado: las coincidencias entre determinadas concepciones estatales sobre la condición del empleo cooperativo y las del Triunvirato. Eliana Lijterman (2018) llevó a cabo un minucioso análisis de documentos emitidos entre 2003 y 2015 por el MTEySS y el MDSN. En 2012, destaca la autora, se incorporan al PRIST, principal línea de subsidios a inempleables del MDSN, dos medidas: 1. El pago de adicionales monetarios por presentismo; 2 . Un complemento por productividad. Concluye Lijterman: 
La valoración del trabajo asociativo, cooperativo y/o comunitario se vio tensionada en los discursos [estatales] que exploramos por la expectativa puesta en el empleo asalariado como modalidad "normal" de trabajo. Como parámetro de deseabilidad, el trabajo asalariado "colonizó" algunos sentidos vinculados con el "trabajo digno" en los discursos especializados, lo cual obturó la posibilidad de reconocerlo por aquellos atributos que le dan un potencial político transformador, asociados con los discursos de la economía social como alternativa frente al capitalismo (...) (2018: 78).

Este tipo de conclusiones se ha in extenso en la literatura especializada en economía social. Se critica con razón la falta de valorización desde el Estado de este tipo de emprendimientos cooperativos desde parámetros propios. No obstante, podemos encontrar una mirada coincidente en el Triunvirato. El punto de coincidencia ya lo analizamos: fijar el mundo asalariado como medida indispensable de valorización y refugio simbólico para aquellos que construyen sus propias formas laborales. El pago de adicionales monetarios por presentismo y por productividad para los beneficiarios de planes sociales aprobado por el Estado es una medida similar a la demanda de creación del Salario Social Complementario o el reclamo de paritarias sociales impulsada por los movimientos sociales.

\section{Sindicalismo popular}

En la primera fase del movimiento piquetero existieron diferentes corrientes de pensamiento en lo que respecta al tipo de articulación que debía darse entre las organizaciones. El Congreso Nacional Piquetero, en 2001, previo a las revueltas del 19 y 20 de diciembre, expuso dos posiciones mayoritarias: por un lado, una tendencia resumida en el denominado bloque matancero liderado por la Federación de Tierra y Vivienda (FTV) y la CCC, que proponía "la posibilidad de unificar el movimiento [de desocupados] y consolidar sus liderazgos" (Svampa, 2005: 246). Se buscaba aunar las múltiples experiencias piqueteras a partir de la constitución de un centro político que las representara. El argumento era que, sin esa unidad centralizada, las organizaciones se diluirían en una dispersión de luchas fácilmente contenidas y/o reprimidas por el Estado.

La férrea oposición hacia esta voluntad centralizadora provino de las organizaciones "autonomistas":

(...) Esta operación por la que un puñado de dirigentes asumen la representación y el liderazgo en nombre del movimiento debilita al movimiento piquetero mismo en dos sentidos: se liquida la multiplicidad en su interior y se otorga a los dirigentes una facultad disciplinaria hacia el interior del movimiento. Esta facultad consiste en un poder discernir quién sí es piquetero y quién no, cuál es la forma correcta de actuar y cuál no, etcétera (Colectivo Situaciones, 2003: 97). 
Aquellos que sostenían este tipo de críticas, como el influyente MTD de Solano en Quilmes, no renegaban de la coordinación - de hecho formaban parte de la Coordinadora Aníbal Verón-, pero sí de los centros representativos escindidos de las bases, es decir, que se abriera una brecha entre lo social (los desocupados) y lo político (una dirigencia). Así lo analizaban:

La coordinación la hacemos, por un lado, con las organizaciones en lucha. Sean diez, veinte o quinientos, pero que estén en lucha. Se plantea mucho el tema de la hegemonía, de que nadie venga con la intención de hegemonizar una lucha, de dirigir. Además siempre planteamos que las coordinaciones de las que participamos no son los ámbitos llamados a encabezar la lucha popular. (...) Cada uno mantiene su independencia, su autonomía (Colectivo Situaciones, 2003: 76).

Finalmente, los sucesivos congresos nacionales piqueteros no pudieron resolver las diferencias de expectativas y objetivos, por lo que no fue posible conformar un movimiento piquetero unificado (Svampa, 2005).

En la segunda fase de los movimientos de desempleados, la divisoria tuvo otra causa. Por un lado, encontramos a las organizaciones que prontamente sumaron su apoyo -e incluso se incorporaron- a la gestión de los gobiernos "progresistas" surgidos entre 2003 y 2015, como el Movimiento Evita y Barrios de Pie; por otro lado, se encuentran aquellas organizaciones que se mantuvieron a distancia y confrontaron con estas administraciones nacionales, como la CCC. En términos sintéticos, la discusión fue entre movimientos sociales que consideraban que el kirchnerismo utilizaba el Estado para cooptar e institucionalizar las luchas sociales y quienes, por su parte, consideraban que el tipo de políticas redistribucionistas, con generación de empleo y promoción del mercado interno, requerían modificar la posición confrontativa con el Estado.

La tercera fase -como ya lo mencionamos- se inicia con el cambio de gobierno acontecido en diciembre de 2015, cuando asume la presidencia Mauricio Macri y se pone en marcha un plan económico de ajuste severo y permanente. ¿Cuál es el otro proceso que determina el pasaje? A modo de cuarta hipótesis: ese proceso es el de la consolidación de la CTEP como un sindicato capaz de centralizar la representación de los trabajadores informales. Dicha centralización se intensifica todavía más cuando se conforma a finales de 2016 el Triunvirato de San Cayetano junto a Barrios de Pie y la CCC. Esta última había perdido esa discusión en 2001, tal como afirmamos anteriormente.

La inmediata decisión de Cambiemos de convertir a las organizaciones en entes administrativos de los planes sociales favoreció el centralismo porque significó la transferencia de recursos económicos muy importantes que robustecieron sus estructuras. No obstante, también lo favoreció porque organizaciones más pequeñas debieron incluirse en la CTEP o en el Triunvirato para obtener planes a los que desde una posición externa no les era posible acceder.

Esta fase se abre, entonces, a partir de un punto de inflexión: ahora sí emerge un centro político, el Triunvirato. En la primera fase del movimiento de desem- 
pleados, no hubo posibilidades de conciliar las posiciones autonomistas con las institucionalistas; en la segunda, las diferencias irreconciliables se dieron en torno a las lecturas opuestas sobre los gobiernos progresistas; entre 2015 y 2019 hubo tres acontecimientos que finalmente lo permitieron: 1. La oposición general a las políticas de ajuste de la alianza Cambiemos; 2. La notable ampliación del presupuesto en materia de subsidios estatales impulsada por el nuevo gobierno para evitar conflictos sociales; 3 . La fijación de los movimientos sociales como entes administrativos de los subsidios durante la primera mitad del mandato de Mauricio Macri.

El testimonio de una referente de la CCC sintetiza esta nueva fase caracterizada por la unidad:

Efectivamente en 2001 faltó la unidad del movimiento obrero, de los desocupados, de las empresas recuperadas. Nosotros dijimos que efectivamente faltó, porque en ese momento del 2001, que lo vivimos todos, la clase obrera tenía miedo de perder el trabajo, no salió a la calle. Y la dirección de la CGT tampoco salió a combatir en las calles. Tampoco. Eso le faltó al 2001. Nosotros somos conscientes de eso: faltó un centro coordinador de todas las luchas. Por eso estamos tan necesitados, e ilusionados, de que esta unidad se plasme y no se rompa. Desde derecha, desde izquierda, desde todos lados se intenta dividir este movimiento que se armó con los Cayetanos. (...) Nosotros privilegiamos la unidad y hacemos mucho esfuerzo, como experiencia de lo que pasó en el 2001, como enseñanza (Referente CCC, La Matanza, 2018).

Si la CCC se aleja en la práctica de concepciones internas históricas como su lejanía con respecto al Estado y su rechazo al sindicalismo tradicional, la CTEP fue quien puso en escena las mayores rupturas con respecto a las dos fases anteriores de las organizaciones piqueteras. Esta Confederación se presenta como un sindicato de nuevo tipo:

Nosotros nos propusimos la construcción de un sindicato de nuevo tipo. Nos propusimos cómo construir una herramienta que nos permitiera a nosotros interpelar frente al Estado por la situación de los trabajadores que no tienen un sindicato que los representen: las empresas recuperadas, los cooperativistas del Plan Argentina Trabaja, los agricultores familiares, los pescadores artesanales. Todo ese mundo que existe (Referente CTEP, Capital Federal, 2018).

En términos formales, la CTEP se organiza en ramas: Cartoneros, Indumentaria, Campesina, Motoqueros, Vendedores Ambulantes, Programas Sociales, Artesanos, Feriantes. En la práctica, esa divisoria es más difusa.

Hugo Serra afirma que "no es el sindicato como organización lo que aparece como novedoso sino una redefinición de la clase obrera en el sentido de una ampliación del significado del trabajo y el sujeto que trabaja (...)" (2017: 33). Este análisis, sin embargo, pierde de vista la historia del movimiento piquetero, dado 
que ya en su nacimiento, a mitad de los noventa, los desocupados se reivindicaban como trabajadores y como parte de la clase obrera. De hecho, se denominaban "trabajadores desocupados". Veamos un testimonio de una militante piquetera en 2002:

Yo no me olvido nunca de lo que dijo una compañera cuando estábamos en un taller de educación popular, trabajando este tema de la identidad. Dijo: “Acá volví a ser yo misma respecto al trabajo. Porque ahora yo soy trabajadora, aunque ni siquiera tenga un plan: soy trabajadora o no explotada". Por eso, la aparente contradicción que implica hablar de trabajadores desocupados es falsa. Porque parecería que un desocupado no puede ser trabajador porque precisamente carece de un empleo: pero nosotros hablamos de trabajar en otro sentido, más profundo, y no simplemente del obrero (Colectivo Situaciones, 2003: 70).

Como afirman Muñoz y Villar, "la novedad es que a la vez que reivindica las luchas de los trabajadores desocupados, la CTEP declara la intención de seguir el modelo sindical argentino" (2017: 22). En ese lugar preciso encontramos el punto de quiebre. La CTEP se conforma como sindicato y toma como referencia a la CGT, es decir, ese viejo modelo sindical tan criticado por los movimientos piqueteros y también por las empresas recuperadas por trabajadores y el conjunto de los movimientos sociales que enfrentaron la economía de mercado en los noventa y primeros años de este siglo. Pero todavía más: la CTEP pretende el ingreso formal a la CGT. Veamos el testimonio de Emilio Pérsico, su principal mentor:

Ese proceso de identificarnos que viene desde aquel entonces, desde fines de los noventa, me dio el momento más lindo de mi vida. Fue cuando [Juan Carlos] Smith [exintegrante del triunvirato que dirigía la CGT] y el Triunvirato que conduce la CGT, veinte años más tarde en el Salón Felipe Vallese [de la CGT], nos reconocieron como trabajadores. Fue un camino largo el que hicimos hasta llegar a ese lugar (Capital Federal, 2018).

Para Pérsico, más que una ruptura con la historia de lucha previa, se trata del devenir lógico y deseado del movimiento piquetero.

En lo que refiere a la decisión de crear un sindicato de nuevo tipo, el antecedente previo podría situarse en el nacimiento de la Central de Trabajadores de la Argentina (CTA) en la década de 1990, cuya principal característica fue la afiliación directa, abriendo la posibilidad de incorporación

de los movimientos de trabajadores desocupados, las organizaciones sociales nucleadas en torno a la demanda de vivienda, las comunidades indígenas, las cooperativas, las organizaciones barriales, las asociaciones de consumidores, etc., instalando una verdadera ampliación y renovación de lo que hasta entonces se concebía como una central sindical (Ventrici, 2012: 9). 
Esta experiencia había nacido con una concepción movimientista del sindicalismo, promoviendo (al menos formalmente) métodos democráticos en la toma de decisiones. ${ }^{6}$ No obstante, a diferencia de la CTEP, la CTA se conforma en abierta oposición y como una crítica radical a la concepción reducida que tenía la CGT sobre quiénes integraban la clase obrera y merecían contar con representación gremial. Justamente, sobre la intención de ingreso de la CTEP a la CGT, un referente de la mesa nacional de CTA afirma: "La pregunta es si la CGT se renovaría con el ingreso de un sindicato que representa a trabajadores informales o si, en realidad, la que envejece prematuramente es la CTEP cuando toma la decisión de ingresar a un aparato burocratizado y anacrónico" (Capital Federal, 2018).

Hasta el momento, la CTEP logró una relativa apertura de la CGT, que se cristalizó en ciertos apoyos a sus luchas, aunque todavía se está lejos de lograr la aceptación de su ingreso. Quinta hipótesis: la CTEP tiene una concepción sumamente contemporánea e innovadora de las dinámicas del mercado laboral, pero se referencia y refugia en un modelo gremial que históricamente excluyó a los trabajadores informales. En otras palabras, la CTEP es una organización propia del siglo XXI pero con un referente gremial del siglo XX. De allí las serias dificultades, más allá de los gestos públicos, en lograr el ansiado ingreso a la central obrera.

Así lo analiza Emilio Pérsico:

Al principio, entonces, fuimos movimientos piqueteros, porque lo que hacíamos eran cortes de ruta; después fuimos organizaciones sociales porque organizábamos el trabajo comunitario; y después armamos nuestro sindicato que es la CTEP. ¡A la mierda! Llegamos al punto máximo: que se empezara a discutir que somos un pedazo de la clase trabajadora, y tenemos ideas y un programa desde este lugar, explicándole al mundo, explicándole a la sociedad y a los políticos, una nueva teoría económica basada en este pedacito de la sociedad. Después, tenemos que juntarnos en la clase trabajadora, volver a la CGT, no solo para resistir al modelo, que lo venimos haciendo muy bien, es una cuestión mucho más estratégica: necesitamos juntarnos con los otros sectores de los trabajadores para construir el germen de un proyecto que sea alternativo a esto (Capital Federal, 2018).

En este punto, emergen las diferencias con la CCC, que rechaza la integración en la CGT:

Es la diferencia que hoy tenemos con la CTEP y con Barrios de Pie también: la sindicalización. Eso para nosotros sería legalizar [la condición de informales]. Nosotros le decimos "no, tenemos que luchar para volver al trabajo formal, a la producción". Tenemos diferencias ahí sobre la sindicalización. En lo que no tenemos diferencias es en que cada compañero tenga obra social. Nosotros no rechazamos a los sindicatos porque tenemos presencia en todas las centrales sindicales. (...) Nosotros estamos discutiendo [sobre el eventual ingreso de la CTEP a la CGT] en qué nos favorecería y en qué nos perjudicaría. Porque una 
vez que vos estás legalizado les pasa lo que les pasa a algunos gremios: la intervención del propio Estado. Y después ingresar con qué tipo de CGT (Referente CCC, La Matanza, 2018).

La CTEP - también dentro del Triunvirato- aprende la lección de las dos fases anteriores: los movimientos sociales requieren de la construcción de instituciones centralizadas, porque de lo contrario corren el riesgo de dispersarse en su capacidad de confrontación y negociación. De allí la invención de un sindicato en el caso de la CTEP, y la creación del Triunvirato a la que apuestan -como vimos en los testimonios- la CCC y Barrios de Pie, con coordinaciones con la propia CGT.

La pregunta, en el caso de la CTEP, es si la sola inclusión de trabajadores noasalariados es sinónimo de construcción de un nuevo sindicato o si se requieren otras prácticas innovadoras. María Inés Fernández Álvarez analiza con precisión que para la CTEP

el trabajo asalariado opera como un horizonte desde el cual se proyectan subjetividades menos como materia a transformar (dejar de ser trabajadores de la economía popular para devenir trabajadores asalariados) y más como fundamento para la producción de derechos colectivos (2018: 24).

A modo de síntesis final, afirmamos que el Triunvirato de San Cayetano navega entre la tradición y la innovación. Se trata de una máquina conectiva entre derechos básicos -salarios, paritarias, aguinaldo, obra social- de un mundo laboral asalariado cada vez más en crisis y trabajadores informales que los perdieron o, lo más inquietante, que jamás fueron beneficiaros en primera persona.

\section{Conclusiones}

Este artículo se propuso analizar el tipo de concepciones y luchas específicas de las principales organizaciones que representan a aquellos sectores que generan sus ingresos por fuera de una relación salarial. Son los considerados inempleables por el mercado laboral formal. A partir de entrevistas con los principales referentes del Triunvirato de San Cayetano -CTEP, Barrios de Pie y la CCC-, pudimos inscribir esta alianza como la tercera fase del movimiento de desempleados nacido a mediados de la década de 1990. La primera (1996-2003) se extendió desde el nacimiento de los movimientos piqueteros y tuvo un epicentro en las revueltas de diciembre de 2001, hasta el inicio del gobierno de Néstor Kirchner. La segunda (2003-2015) estuvo signada por la relación entre los movimientos piqueteros y los gobiernos denominados progresistas. Esta tercera fase (2015-2019) se inaugura con el cambio de gobierno nacional y el fin del ciclo kirchnerista. Se relaciona con la consolidación de la CTEP, a partir del surgimiento del Triunvirato de San Cayetano, como un inédito centro político representativo de los trabajadores informales.

En la primera fase hubo dos discusiones centrales: si la auto-organización de los desempleados mediante proyectos productivos de baja escala era transitoria -hasta que retornara una etapa de crecimiento industrial-, o bien si se trataba de un ca- 
mino definitivo. La otra tensión pasaba por si era estratégico forjar una estructura organizativa que centralizara el comando de las luchas, o si había que evitar la creación de un centro político que implicara la separación entre las bases y las dirigencias. En la segunda fase, la discusión tuvo como protagonistas a quienes preferían apoyar y acompañar a los gobiernos progresistas, y a aquellos que planteaban que las organizaciones debían mantenerse a distancia y con una postura crítica con respecto a estas administraciones estatales.

En la etapa actual, por su parte, los líderes de la CTEP, Barrios de Pie y la CCC comprenden que la dinámica del mercado laboral cerró una discusión: para al menos un tercio de la población trabajadora no habrá posibilidades de ingreso en una relación asalariada. A su vez, la precariedad se torna cada vez más intensa entre los asalariados. Este certero diagnóstico acerca de la fisonomía del empleo en el capitalismo en su fase financiera (avalado por todas las estadísticas en las últimas décadas) hace que en el horizonte de estas organizaciones ya no aparezca el trabajo formal como un objetivo verosímil, aun cuando públicamente no renuncien por completo a ese reclamo, como en el caso de la CCC. Entonces, si ya no es posible volver a ser asalariados, los objetivos mutan: los trabajadores de la economía popular deben ser formalmente reconocidos por el Estado a partir de la obtención de ciertos derechos de los que gozan los trabajadores formales (salario, obra social, aguinaldo, paritarias).

Nuestra conclusión remarca una paradoja fundacional que radica en la audacia de poner en diálogo figuras y narrativas que vertebraron un mundo asalariado en descomposición con trabajadores que justamente fueron expulsados de manera crónica de ese universo. Ya no quieren ser asalariados, sino informales (trabajadores populares) que gozan algunos de los derechos principales de los asalariados. La aprobación del Salario Social Complementario, hasta el momento el logro más resonante para estas organizaciones, posibilita el reconocimiento de las actividades productivas de la economía popular como trabajos por parte del Estado, y a sus protagonistas como trabajadores. Lo que antes era un oxímoron (salario e informalidad laboral), ahora es una relación complementaria. Los referentes entrevistados afirmaron la importancia que tiene para los trabajadores de la economía popular todavía poder incluirse en una trama simbólica correspondiente al mundo asalariado. La invención de formas post-salariales de generar ingresos, así como la creación de un sindicato de nuevo tipo en el caso de la CTEP, no derivan en la invención de nuevas narrativas y reivindicaciones sino en una innovadora operación que recombina figuras y escenarios laborales del siglo XXI con lenguajes y derechos laborales inventados por el sindicalismo en el siglo XX. Dicho de otra manera: las organizaciones -en especial la CTEP- tienen una concepción muy precisa acerca de las dinámicas del mercado laboral en la fase financiera del capitalismo, pero su horizonte es un modelo propio del capitalismo en su extinta fase fordista.

En este contexto, la CTEP logró consolidarse como una centralidad política capaz de representar a los trabajadores populares (informales). Se trata de una centralización que supo intensificarse todavía más a partir del momento en el que se articula con Barrios de Pie y la CCC para formar el Triunvirato de San Cayetano, 
en ocasión de las multitudinarias movilizaciones organizadas para lograr la aprobación de la Ley de Emergencia Social. Allí encontramos un punto de inflexión con respecto a las dos fases previas de los movimientos de desempleados, caracterizadas por las fracturas y las divisiones.

Para finalizar, afirmamos que más que determinar si el Triunvirato y la CTEP son innovadores o conservadores, desde nuestra perspectiva es pertinente entenderlos como máquinas conectivas capaces de hacer confluir en un mismo plano narrativas, estructuras, derechos y sujetos laborales tanto nuevos y como tradicionales. De las tensiones dentro de ese plano tan abigarrado depende la subsistencia de millones de trabajadores informales o, para ser más precisos, de los inempleables.

\section{Referencias}

1. En 2018 el Ministerio de Trabajo, Empleo y Seguridad Social perdió su rango ministerial para ser convertido en una Secretaría bajo la órbita del Ministerio de Producción.

2. El nombre San Cayetano se vincula con una multitudinaria marcha que protagonizaron en 2016 estas tres organizaciones sociales desde la iglesia de San Cayetano (Capital Federal) hasta la Plaza de Mayo en reclamo de la aprobación legislativa de la Ley de Emergencia Social bajo la consigna "Pan, Paz y Trabajo".

3. Se refiere a Amalita Fortabat, reconocida empresaria -ya fallecida-, dueña de la cementera Loma Negra.

4. Mauricio Macri, actual presidente de la Nación, integrante de una familia empresaria cuyos negocios están ligados a múltiples ramas industriales: automotriz, energética, etcétera.

5. La Asignación Universal por Hijo, iniciada en 2009, es un seguro social que se otorga a personas desocupadas, que trabajan como empleados en negro o que ganan menos del salario mínimo, vital y móvil. Es un derecho por cada hijo menor de 18 años e hijo con discapacidad.

6. Otro movimiento con raigambre sindical que tuvo un lugar protagónico en la primera fase de los movimientos piqueteros es la Corriente Clasista y Combativa, actual integrante del Triunvirato de San Cayetano.

\section{Bibliografía}

Abal Medina, P. (2017). Las formas políticas del trabajo. Revista Anfibia. Buenos Aires, Argentina. Disponible en: http://revistaanfibia.com/ensayo/las-formas-politicas-del-trabajo/

Bertranou, F. y Casanova, L. (2013). Informalidad laboral en Argentina: Segmentos críticos y políticas para la formalización. Buenos Aires, Argentina: Organización Internacional del Trabajo.

Bruno, D., Coelho, R. y Palumbo, M. (2017). Innovación organizacional e institucionalización conflictiva de las organizaciones de la Economía Popular. El caso de la Confederación de Trabajadores de la Economía Popular (CTEP). Argumentos, Revista de Crítica Social, 90-112.

Colectivo Situaciones (2003). Hipótesis 891: más allá de los piquetes. Buenos Aires, Argentina: Tinta Limón.

Fernández Álvarez, M. I. (2018). Más allá de la precariedad: prácticas colectivas y subjetividades políticas desde la economía popular argentina. Iconos. Revista de Ciencias Sociales, 62, 21-38.

Fernández Mouján, L. (2018). La Confederación de Trabajadores de la Economía Popular (CTEP): hacia la representación de un nuevo tipo de trabajador. En E. Moler (Ed.), Debates, alcances y encrucijadas de la organización de los sectores populares: la CTEP, una nueva experiencia sindical (pp. 45-63). Buenos Aires, Argentina: Editorial Universidad Metropolitana para la Educación y el Trabajo (UMET).

Fornillo, B. (2008). Derivas de la matriz nacional popular: el pasaje de la movilización a la estatización del Movimiento Barrios de Pie durante el kirchnerismo (2001-2007). En S. Pereyra, G. Pérez y F. 
Schuster (Eds.), La huella piquetera. Avatares de las organizaciones de desocupados después de 2001 (pp. 183-203). Buenos Aires, Argentina: Ediciones Al margen.

Gago, V. (2015). La razón neoliberal: economías barrocas y pragmática popular. Buenos Aires, Argentina: Tinta Limón.

Gago, V. (2016). Diez hipótesis sobre las economías populares (desde la crítica a la economía política). Revista Nombres, 25 (30), 179-198.

Grabois, J. (2018). La clase peligrosa. Buenos Aires, Argentina: Planeta.

Hopp, C. (2015). Identidades laborales de destinatarios del Programa Ingreso Social con Trabajo Argentina Trabaja. Revista Trabajo y Sociedad, 24, 207-223.

Hudson, J. P. (2018). Políticas públicas de promoción de la autogestión de la alianza Cambiemos. Revista Perspectivas de Políticas Públicas, 8, (15), 173-205.

Lijterman, E. (2018). Políticas de promoción de la economía social en Argentina: una aproximación desde los saberes expertos. Iconos. Revista de Ciencias Sociales, 62, 65-85.

Lo Vuolo, R. (2010). El programa "Argentina Trabaja" y el modo estático de regulación de la cuestión social en el país. Documento de Trabajo $\mathrm{N}^{\mathrm{0}} 75$. Centro Interdisciplinario para el Estudio de Políticas Públicas, marzo, 1-20.

Massetti, A. (2009). La década piquetera. Acción colectiva y protesta social de los movimientos territoriales urbanos. Buenos Aires, Argentina: Trilce.

Ministerio de Trabajo, Empleo y Seguridad Social (2013). Una década de trabajo, una década ganada. Buenos Aires, Argentina: MTEySS. Disponible en: http://www.trabajo.gob.ar/downloads/ destacados/131104_notas_una-decada-ganada.pdf

Muñoz, M. A. y Villar, L. I. (2017). Confederación de Trabajadores de la Economía Popular (CTEP en la CGT). Entre la organización sindical y el conflicto político-social (Argentina, 2011-2017). Crítica y Resistencias. Revista de conflictos sociales latinoamericanos, 5, 22-52.

Natalucci, A. (2012). Políticas sociales y disputas territoriales. El caso del programa Argentina Trabaja. Revista de Perspectivas de Políticas Públicas, 2, (3), 126-147.

Natalucci, A. (2014). La recreación de la gramática movimientista de acción colectiva: movimientos sociales y nuevas institucionalidades. En P. Forni y L. Castronuevo (Eds.), Ni piqueteros ni punteros: organizaciones populares durante el kirchnerismo (pp. 149-166). La Plata, Argentina: Edulp.

Palomino, H. y Dalle, P. (2012). El impacto de los cambios ocupacionales en la estructura social de la Argentina: 2003-2011. Revista de Trabajo, 10, 205-223.

Perelmiter, L. (2010). Militar el Estado. La incorporación de movimientos sociales de desocupados en la gestión de políticas sociales. Argentina (2003-2008). En E.Villanueva, A. Massetti y M. Gómez (Eds.), Movilizaciones, protestas e identidades políticas en la Argentina del bicentenario (pp. 132152). Buenos Aires, Argentina: Lugar.

Pérsico, E. y Grabois, J. (2014a). Nuestra realidad. Primer cuadernillo. Buenos Aires, Argentina: Asociación Civil de los Trabajadores de la Economía Popular.

Pérsico, E. y Grabois, J. (2014b). Nuestra organización. Segundo cuadernillo. Buenos Aires, Argentina: Asociación Civil de los Trabajadores de la Economía Popular.

Pérsico, E. y Grabois, J. (2014c). Nuestros Objetivos. Tercer cuadernillo. Buenos Aires, Argentina: Asociación Civil de los Trabajadores de la Economía Popular.

Pérsico, E. y Grabois, J. (2014d). Nuestra lucha. Cuarto cuadernillo. Buenos Aires, Argentina: Asociación Civil de los Trabajadores de la Economía Popular.

Pérsico, E. y Navarro, F. (Eds.). (2017). Economía Popular. Los desafios del trabajo bajo patrón. Buenos Aires, Argentina: Colihue.

Rajland, B. y Campione, D. (2006). Piqueteros y trabajadores ocupados en la Argentina de 2001 en adelante. Novedades y continuidades en su participación y organización en los conflictos. En F. Caetano (Ed.), Sujetos sociales y nuevas formas de protesta en la historia reciente de América Latina (pp. 297-330). Buenos Aires, Argentina: Clacso.

Scarfó, G., Hopp, M. y Highton, C. (2009). Reflexiones en torno al concepto de inempleabilidad: consideraciones para pensar la política social. Revista Plaza Pública, 2 (2), 8-20.

Schuttenber, M. (2014). El campo nacional y popular durante el kirchnerismo: una aproximación 
a las diferentes experiencias históricas, identidades y tradiciones políticas que reconfiguraron ese espacio desde el 2003. En P. Forni y L. Castronuevo (Eds.), Ni piqueteros ni punteros: organizaciones populares durante el kirchnerismo (pp. 99-127). La Plata, Argentina: Edulp.

Serra, H. (2017). La CTEP Córdoba y la emergencia social. Un estudio de marcos de la acción colectiva en los trabajadores de la economía popular. Revista Sociales Investiga. Escritos académicos, de extensión y docencia, 4, 24-40.

Svampa, M. (2005). La sociedad excluyente. Buenos Aires, Argentina: Taurus.

Svampa, M. y Pereyra S. (2004). Entre la ruta y el Barrio: Las organizaciones piqueteras. Buenos Aires, Argentina: Biblos.

Ventrici, P. (2012). La resignificación de una marca histórica. El panorama actual de la representación sindical en el lugar de trabajo. Revista Estudios del Trabajo, 43/44, 25-48.

Vuotto, M. (2011). El cooperativismo de trabajo en la Argentina: contribuciones para el diálogo social. Lima, Perú: OIT/ Programa Regional para la Promoción del Diálogo y la Cohesión Social en América Latina. Disponible en: https:// www.ilo.org/wcmsp5/groups/public/---americas/---ro-lima/ documents/publication/wcms_179395.pdf

Zibechi, R. (2008). Territorios en resistencia. Cartografía política de las periferias urbanas latinoamericanas. Buenos Aires, Argentina: LaVaca.

Recibido: 04/03/2019. Aceptado: 30/12/2019.

Juan Pablo Hudson, "La representación de los trabajadores informales: el Triunvirato de San Cayetano". Revista Temas y Debates. ISSN 1666-0714, año 24, número 39, enero-junio 2020, pp. 35-58. 